\title{
A Whole Genome Scanning for QTL affecting Leg Weakness and Its Related Traits in a White Duroc $\times$ Erhualian Resource Population
}

\author{
Dissertation \\ to obtain the $\mathrm{Ph}$. D. degree \\ in the Faculty of Agricultural Sciences, \\ Georg-August-University Göttingen, Germany \\ Presented by \\ Yuanmei Guo
}

Born in Jiangxi/P. R. China

Göttingen, December 2008 
D7

1. Name of referee: Prof. Dr. Dr. Bertram Brenig

2. Name of co-referee: Prof. Dr. Henner Simianer

Date of dissertation: 11th December, 2008 
To my deeply beloved family 


\section{Table of Contents}

Publications of this dissertation

Abstract

Abbreviations

Chapter 1: General introduction

Chapter 2: A combined QTL analysis of two populations

Chapter 3: Construction of a porcine whole-genome linkage map

Chapter 4: QTL for leg weakness and it related traits in pigs

Chapter 5: QTL for bone growth and quality in pigs

Acknowledgements 45

List of publications 46

Curriculum vitae 49 


\section{Parts of this dissertation have been published}

1. Guo Y. -M., Lee G. J., Archibald A. L., Haley C. S. (2008) Quantitative trait loci for production traits in pigs: a combined analysis of two Meishan $\times$ Large White populations. Animal Genetics 39(5): 486-95.

2. Guo Y. -M., Mao H. -R., Ren J., Yan X. -M., Duan Y. -Y., Yang G. -C., Ren D. -R., Zhang Z. -Y., Yang B., Ouyang J., Brenig B., Haley C. S., Huang L. -S. (2009) A linkage map of the porcine genome from a large scale White Duroc $\times$ Erhualian resource population and evaluation of factors affecting recombination rates. Animal Genetics 40(1): 47-52.

3. Mao H. -R.*, Guo Y. -M.*, Yang G. -C., Yang B., Ren J., Liu S. -F., Ai H. -S., Ma J. -W., Brenig B., Huang L. -S. (2008) A Genome-wide scan for quantitative trait loci affecting limb bone lengths and areal bone mineral density of the distal femur in a large White Duroc $\times$ Erhualian $\mathrm{F}_{2}$ population. BMC Genetics 9: 63 .

4. Guo Y. -M., Ai H. -S., Ren J., Wang G. -J., Wen Y., Mao H. -R., Lan L. -T., Ma J. -W., Brenig B., Rothschild M. F., Haley C. S., Huang L. -S. (2009) A whole genome scanning for quantitative trait loci for leg weakness and its related traits in a large $F_{2}$ intercross population between White Duroc and Erhualian. Journal of Animal Science (Accepted). 


\section{Abstract}

A linkage map comprising 194 microsatellite markers across the pig genome was constructed with a large scale White Duroc $\times$ Erhualian resource population. The marker order on this linkage map was consistent with the USDA-MARC reference map except for 2 markers on pig chromosome (SSC) 3, 2 markers on SSC13 and 2 markers on the $\mathrm{X}$ chromosome. The length of the sex-average map $(2,344.7 \mathrm{cM})$ was nearly the same as those of the USDA-MARC and the NIAI maps. A highly significant heterogeneity in recombination rates between sexes was observed. The female autosomes had higher average recombination rates than the male autosomes except for SSC1 and SSC13. However, recombination rates in the pseudoautosomal region were greater in males than in females. These observations are consistent with the previous reports. The recombination events on each paternal and maternal chromosome of $F_{2}$ animals were also inferred by SimWalk2. Recombination rates were not significantly affected by the age (in the unit of day) and the parity of $F_{1}$ animals. However, the recombination rates on the paternal chromosomes were affected by the mating season of $F_{1}$ animals. This could represent an effect of environmental temperature on spermatogenesis.

To detect quantitative trait loci (QTL) for leg weakness in pigs, a total of 1,484 $\mathrm{F}_{2}$ pigs were recorded for their leg scores (at $76 \mathrm{~d}$ and $213 \mathrm{~d}$ ) and gait scores (at $153 \mathrm{~d}$ and 223 d) in the White Duroc $\times$ Erhualian resource population. Moreover, the lengths of the limb bones, the areal mineral density of the femoral bone (aBMD) and the length and the weight of the biceps brachii muscle were recorded after these $F_{2}$ animals were harvested at 240 d. A whole genome scan was performed with 194 microsatellite markers in the resource population to identify QTL for these traits. A total of 79 QTL were detected, including 35 at the $1 \%$ genome-wide significant level and 9 at the 5\% genome-wide significant level. Seventy-two of the 79 QTL showed significant additive effects and 20 of the 79 QTL had significant dominance effects. 
At least two QTL were detected for each trait except for the leg score at $76 \mathrm{~d}$, for which no QTL was identified. Some of QTL for leg scores, gait scores and lime bone lengths confirmed previous findings. Eighteen QTL for the weight and the length of the biceps brachii muscle and two QTL for the aBMD were detected in present study. To our knowledge, this was the first report about QTL for the three traits in pigs. Two chromosome regions each on SSC4 and SSC7 showed significant and multiple associations with leg weakness and the growth of the biceps brachii muscle and the lime bones, which are worthwhile for further investigation.

Combined analysis of data from two or more resource populations can improve the power and accuracy of QTL mapping and allow some cross-validation of results. In this study, we performed a genome-wide scan using combined data from two $\mathrm{F}_{2}$ populations derived from a cross between Large White and Chinese Meishan pigs. A total of 739 pigs were included in the analysis. In total 187 markers were genotyped in the two populations, including 115 markers genotyped in both populations, and these markers covered 2,282 $\mathrm{cM}$ of the pig genome with an average of $13.58 \mathrm{cM}$ between adjacent markers. Seven traits (teat number, birth weight, weaning weight, test-end weight, fat depth at shoulder, fat depth at mid back and fat depth at loin) were analyzed for both individual populations and the combined population. There were 9 $(2,10), 1(4,4)$ and $14(5,18)$ QTL that achieved 1\% genome-wide, 5\% genome-wide and suggestive significance levels, respectively, in population 1 (population 2, combined population). Additive effects of QTL detected in the two populations at all significance levels were largely consistent suggesting that the QTL represent real genetic effects, but this was not the case for dominance or imprinting effects. There were also a number of significant interactions between detected QTL effects and population. 


\section{Abbreviations}

aBMD

AIL

BMD

$C_{a}$

$C_{d}$

$\mathrm{CI}_{0.95}$

$\mathrm{cM}$

DXA

FGS

FLS

$I G F 2$

LOD

LR

MARC

ML

NIAI

PiGMaP

PRKAG3

QTL

RFLP

RGS

RLS

SAS

SNP

SSC

USDA areal bone mineral density

advanced intercross lines

bone mineral density

additive coefficient

dominance coefficient

$95 \%$ confidence interval

Centimorgan

dual energy X-ray absorptiometry

gait score of front legs

front leg score

insulin-like growth factor 2

likelihood of odds

likelihood ratio

Meat Animal Research Center

maximum likelihood

National Institute of Animal Industry of Japan

European Pig Gene Mapping Project Consortium

protein kinase AMP-activated gamma 3

quantitative trait locus

restriction fragment length polymorphism

gait score of rear legs

rear leg score

Statistics Analysis System

single nucleotide polymorphism

Sus scrofa chromosome

United States Department of Agriculture 


\section{1}

General Introduction 


\subsection{Introduction}

Pork is the most popular meat in the world, and occupies $43 \%$ of red meat market in the world (Rothschild and Ruvinsky, 1998). As an animal domesticated over 7,000 years ago and a kind of very important agricultural livestock, pigs have undergone artificial selections in the history. In recent decades, the artificial selections imposed on pigs became more intensive, and some economical traits of the pig, such as average daily gain (ADG) and backfat thickness, have got a substantial improvement. However, artificial selections for production traits have adverse effects on leg structures, and poor leg structures cause leg weakness (Lee et al., 2003). Leg weakness or leg soundness disorder becomes more popular and has resulted in huge economical loss in the pig industry (Rothschild and Christian, 1988). Leg weakness can be evaluated with leg scores and gait scores, and is related with the weight and the length of the biceps brachii muscle and the length and the mineral density (BMD) of limb bones (Draper et al., 1991), but the genetic architecture of leg weakness is still poorly understood.

Combined analysis of data from two or more resource populations can improve the power and accuracy of quantitative trait locus (QTL) mapping and allow some cross-validation of results. But just few joint analyses of specific chromosomes have been reported (Walling et al., 2000; Kim et al., 2005; Pérez-Enciso et al., 2005).

In the present study, a three-generation population was developed by a cross between two White Duroc boars and 19 Erhualian sows at Jiangxi Agricultural University (Ren et al., 2006). The lengths of limb bones, the weight and the length of the biceps brachii muscle, leg scores and gait scores of the $\mathrm{F}_{2}$ animals were recorded. A total of 194 microsatellite markers were genotyped and a linkage map was constructed. The effects of some environmental factors including sex and season on 
recombination ratios were also investigated. Furthermore, a whole genome scan was performed to identify QTL for leg weakness and its related traits. Finally, to evaluate the merits of the joint data QTL analysis, a genome-wide scan was performed using combined data from two $\mathrm{F}_{2}$ populations derived from a cross between Large White and Chinese Meishan pigs.

\subsection{Linkage maps of pig}

Linkage map, also called genetic map, is the fundament of the QTL mapping, and a lot of efforts have been devoted to construct and extend the swine linkage map in the recent decades. Until now, four linkage maps have been reported, and more than 3,000 genetic markers have been assigned on the swine genome. The four genetic maps are the Meat Animal Research Center of United States Department of Agriculture (USDA-MARC) map (Rohrer et al., 1994; Rohrer et al., 1996), the European Pig Gene Mapping Project consortium (PiGMaP) map (Archibald et al., 1992; Archibald et al., 1995), the Scandinavian map (Ellegren et al., 1994; Marklund et al., 1996) and the National Institute of Animal Industry of Japan (NIAI) map (Mikawa et al., 1999). On these linkage maps, most of the common markers have the same order except for few closely linked markers having different orders. But the distances between adjacent markers are more variable than the order, which might be caused by the small population size (the number of $F_{2}$ animals varying from 94 to 200 in the four reference populations). To improve the swine linkage map, a large scale experimental population with more informative meioses is required (Rohrer et al., 1996). 


\subsubsection{The factors affecting the linkage maps}

It has been reported that recombination occurs unevenly across chromosomes, and their occurrences are also influenced by several other factors, such as sex, age of the animal producing the gamete and environmental temperature (Morgan et al., 1925; Simchen and Stamberg, 1969).

\subsubsection{Sex}

Sex has remarkably significant effects on recombination frequency in a number of species, such as human, cattle, horse, dog, chicken (Dunn and Bennett, 1967; Callan and Perry, 1977; Andersson and Sandberg, 1984; Broman et al., 1998; Groenen et al., 1998; Neff et al., 1999). The general tendency for recombination is less frequent in the heterogametic sex. Pig is not an exception; the recombination of the female is greater than that of the male in most chromosomal regions (Archibald et al., 1995; Marklund et al., 1996; Rohrer et al., 1996; Mikawa et al., 1999).

The average ratios of the recombination rates between females and males were 1.402, 1.545 and 1.303 in the Scandinavian, the NIAI and the PiGMaP maps, respectively. The USDA-MARC map did not consider the different recombination rates between sexes because the population size was too small to get a reliable estimate. On the four reported maps, linkage maps of all chromosomes were longer in females than in males except for few chromosomes. On the NIAI and the PigMap maps, although females had higher recombination rates at both ends of SSC1, they had lower recombination rate in the SW781-SW974 region, which ultimately caused the male linkage map to be longer than the female (Figure 1). Besides SSC1, the linkage maps of SSC2, SSC9, SSC13 and SSC14 were also longer in males than in females on the PigMap map. On the Scandinavian map, only the linkage map of SSC13 was longer in males than in females. 


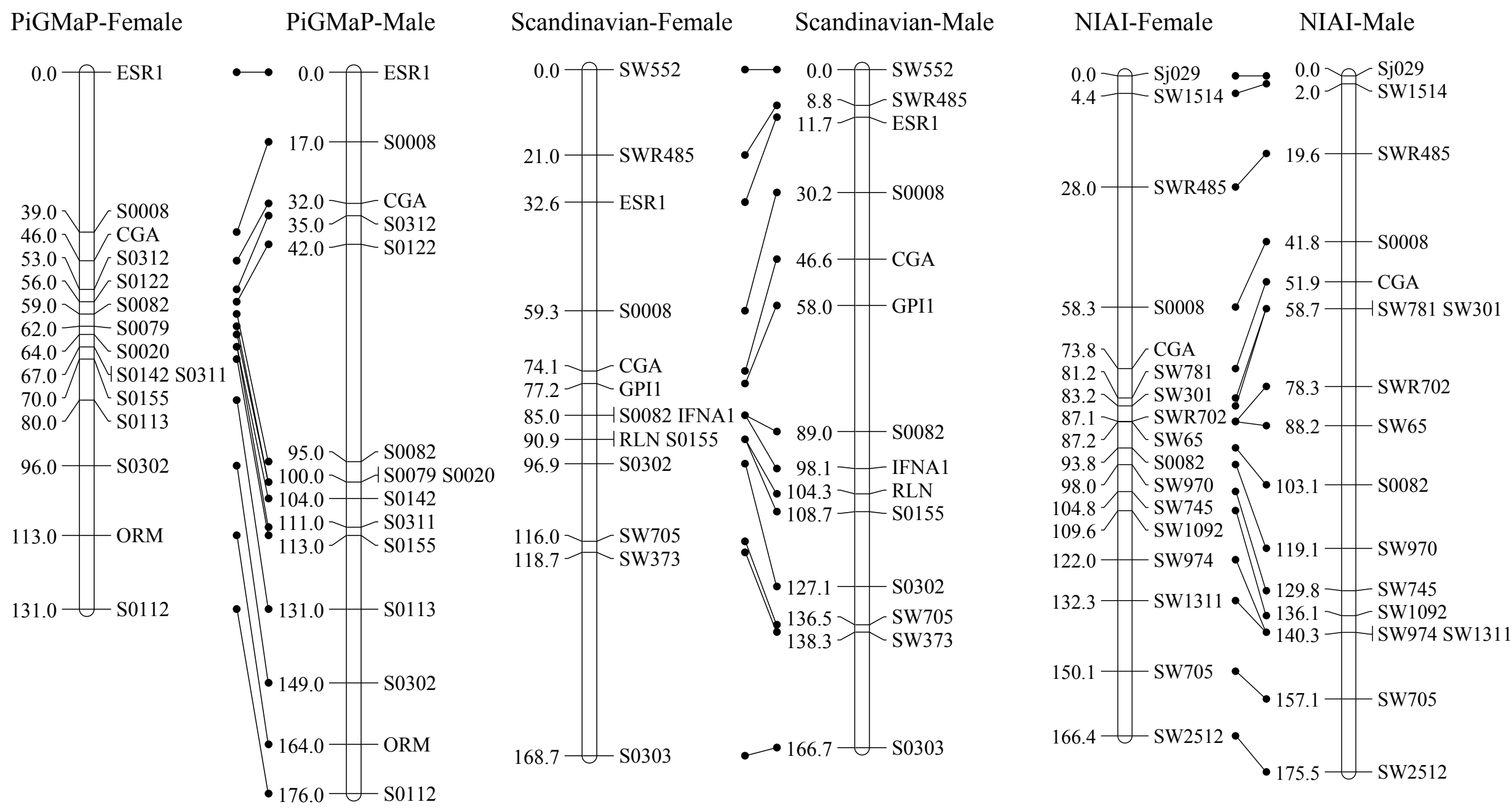

Figure 1 The sex-specific linkage maps of SSC1 from the PiGMaP, the Scandinavian and the NIAI maps. 


\subsubsection{Age of the animal producing the gamete}

The age of the animal producing the gamete is another factor affecting the recombination. Bridges reported as early as 1915 that crossing over in Drosophila varied with the age of the mother, which was confirmed later (Redfield, 1966). In $C$. elegans, recombination frequency varied with the maternal age (Rose and Baillie 1979). In humans, some studies also indicated that the recombination was related with age (Weitkamp, 1973), but it was not confirmed in other studies (Renwick and Schulze 1965; Weitkamp et al., 1973; Lange et al., 1975; Elston et al., 1976). There was no significant evidence of an age effect in the horse (Andersson and Sandberg, 1984).

\subsubsection{Environmental temperature}

The environmental temperature also has an influence on the recombination rate. In $C$. elegans, recombination frequency was increased two times when the ambient temperature increased from $13.5^{\circ} \mathrm{C}$ to $26^{\circ} \mathrm{C}$ in some regions on linkage groups $I$ and $V$ (Rose and Baillie, 1979). Temperature shock treatments at $0{ }^{\circ} \mathrm{C}$ and $37{ }^{\circ} \mathrm{C}$ usually increased recombination frequency in Drosophila (Grushko et al., 1991). In Coprinus lagopus, both descending and ascending temperature could increase the recombination frequency $(\mathrm{Lu}, 1974)$. The increased recombination frequency by low temperature might be attributable to the increased duration of pachytene, because the recombination frequency is a function of the duration of pachytene. The longer the homologous chromosomes are holding together, the higher is the recombination frequency ( $\mathrm{Lu}, 1974)$.

\subsubsection{Genes}

The recombination rate can be influenced by genetic variation (Simchen and Stamberg, 1969; Maynard Smith, 1978). Domesticated animals are different from 
natural populations for having unusually high chiasmata counts (Burt and Bell, 1987). In C. elegans, a recessive mutation (rec-1) can expand map distances across the gene cluster and contract map distances near the right end of the chromosome I (Zetka and Rose, 1995)

\subsubsection{Location on the chromosome}

Short chromosomal arms have higher recombination rates than long arms, and recombination rates are more frequent in telomeric regions than in pericentric regions (Marklund et al., 1996; Rohrer et al., 1996).

\subsubsection{The length of the swine linkage map}

The estimated length of the sex-average linkage map was $2,470 \mathrm{cM}$ on the USDA-MARC map (Rohrer et al., 1996), 2,500 cM on the Scandinavian map (Marklund et al., 1996), and 2,561.9 cM on the NIAI map (Mikawa et al., 1999). Considering that the NIAI map extended the USDA-MARC map about $48.5 \mathrm{cM}$ at the ends of SSC1, SSC5, SSC11 and SSCX, the sizes of these three maps have no significant difference, and 2,500 $\mathrm{cM}$ is possible the best estimated length. The PiGMaP map did not cover the whole genome, so the reported 1,800 cM on this map obviously underestimated the length of the sex-average linkage map (Archibald et al., 1995). The lengths of male-specific (female-specific) linkage maps were 1,931.3 $(2,984) \mathrm{cM}, 1,650(2,150) \mathrm{cM}$ and $1,830(2,565) \mathrm{cM}$ in NIAI, PiGMaP and Scandinavian maps, respectively (Archibald et al., 1995; Marklund et al., 1996; Mikawa et al., 1999). 


\subsection{QTL mapping}

Mapping of QTL is the first step of positional cloning and position candidate gene approach. Following the first study of QTL mapping in pigs in 1994 (Andersson et al., 1994), a number of QTL studies have been carried out (Rothschild et al., 1995; Knott et al., 1998; Lee et al., 2003; Ren et al., 2006). So far a total of 1,831 QTL across the pig genome have been recorded in the pig QTL database (PigQTLdb: http://www.animalgenome.org/QTLdb/pig.html). Studies of QTL mapping have contributed to the identification of some economically important genes in pigs, such as the protein kinase AMP-activated gamma 3 gene (PRKAG3) (Milan et al., 2000) and the insulin-like growth factor 2 gene (IGF2) (Van Laere et al., 2003).

\subsubsection{Resource family}

A specific experimental population, namely resource family, is required for QTL mapping. Resource families include backcross populations, $F_{2}$ (the second filial generation) populations, advanced intercross lines (AIL) and other complex populations.

\subsubsection{Backcross population}

To produce a backcross population, two parental lines cross each other to produce the first filial generation $\left(F_{1}\right)$, and then $F_{1}$ animals mate with the animals from the parental lines to generate the backcross population. In a backcross population, the segregation and recombination events of each backcross animal can be traced only in one gamete (the male or the female $\mathrm{F}_{1}$ gamete). But in an $\mathrm{F}_{2}$ population, they can be traced in both gametes (the male and the female $\mathrm{F}_{1}$ gametes). At the same population size, backcross populations have less statistic power than $F_{2}$ populations and are gradually replaced by $\mathrm{F}_{2}$ populations. 


\subsubsection{2 $\mathrm{F}_{2}$ population}

The first step to produce an $\mathrm{F}_{2}$ population is the same as that for the development of a backcross population, but the second step is different. Instead of mating to the paternal lines, $F_{1}$ individuals intercross to get $F_{2}$ animals. The $F_{2}$ population is widely used in QTL mapping now, because they are more powerful than other populations (Knott et al., 1998; de Koning et al., 2001; Ren et al., 2006).

\subsubsection{Advanced intercross lines}

Advanced intercross lines (AIL) are based on $F_{2}$ populations. The $F_{2}$ population keeps randomly and sequentially intercrossing for $n$ generations, resulting in an advanced intercross line (Darvasi and Soller, 1995). Sequentially intercrossing of AIL increases the probability of recombination between loci, so AIL has high resolution of QTL map position. However, construction of AIL is time consuming, especially for livestock with long generation intervals, so AIL populations are not widely engaged in QTL mapping in farm animals. Usually, they are applied in QTL fine mapping in crops or small animals with short generation intervals (Iraqi, 2000; Iraqi et al., 2000; Wang et al., 2003a; Wang et al., 2003b; Balint-Kurti et al., 2007).

\subsubsection{Other complex populations}

For the large livestock species, such as dairy cattle, the experimental populations described above are impractical for establishment because of the cost and the time consumption. The natural populations from farms can be applied in QTL mapping in these species with less statistical power. The half-sib design and the grand-daughter design are two mainly methods used in QTL mapping of dairy cattle (Heyen et al., 1999; Bennewitz et al., 2003; Mariasegaram et al., 2007). 


\subsubsection{Marker selection}

A genetic marker is a segment of DNA with an identifiable physical location on a chromosome and tracable inheritance. A genetic marker can be a gene or a fragment of DNA with unknown function, for example an anonymous marker.

\subsubsection{Classification of genetic markers}

There are four kinds of genetic markers: type I, type II, type III and type IV. A type I marker is a segment of a gene; a type II marker is an anonymous sequence, including restriction fragment length polymorphism (RFLP) and microsatellite; a type III marker is a single nucleotide polymorphism (SNP); and a type IV marker is a copy number variation. The type II marker is widely used in QTL mapping because it is more polymorphic than the others. The type III marker is usually applied in the QTL fine mapping for its abundance in the genome.

\subsubsection{Criterion of maker selection}

Marker selection is a key step for QTL mapping. The criteria for the selection of genetic marker are listed below: (1) coverage of the whole swine genome at an interval of 20 to $30 \mathrm{cM}$; (2) informative in the population; (3) ease to genotype; (4) usage in other studies (Lee et al., 2003).

\subsubsection{Information content and segregation distortion}

Information content and segregation distortion are two factors reflecting the quality of the genotype data. In general, information content is increasing with the increment of the marker's polymorphism, and segregation distortion is decreasing with the enhancement of the accuracy of the marker's genotypes. 


\subsubsection{Information content}

Information content indicates how much information that marker can provide at any location on the genome. If the location is full informative for an $F_{2}$ animal, then the QTL genotype of the $F_{2}$ animal can be known without error. So the additive coefficient $\left(C_{a}\right)$ of the $\mathrm{F}_{2}$ animal is 1 (when the QTL genotype of this animal is QQ), 0 (Qq or qQ) or -1 (qq), and the dominance coefficient $\left(C_{d}\right)$ is 1 (Qq or qQ) or 0 (QQ or qq). If the location is completely non-informative for an $F_{2}$ individual, then all of the probabilities of the QTL genotypes of QQ, Qq, qQ and qq are 0.25 , and $C_{a}$ of the animal is 0 (equal to 0.25 minus 0.25 ) and $C_{d}$ is 0.5 (equal to 0.25 plus 0.25 ). The variance of $C_{a}$ plus twice the variance of $C_{d}$ is used to indicate the information content, which varies between 0 and 1.125 (Knott et al., 1998).

\subsubsection{Segregation distortion}

There are two kinds of segregation distortion, one is an excess of alleles from either of the original lines and the other is an excess or lack of heterozygotes (Knott et al., 1998).

The expected values of $C_{a}$ and $C_{d}$ are zero and 0.5 in an $\mathrm{F}_{2}$ population, respectively. When the alleles from one original line excess those from the other, the population mean of $C_{a}$ tends to 1 or -1 . If the heterozygote is more or less than its expected value, then the population mean of $C_{d}$ tends to 1 or 0 . A $t$ test can determine whether a segregation distortion exists at a given location on the genome. The deviations of the population mean of $C_{a}$ and $C_{d}$ from their expected values probably arise from the genotypic errors in the data.

\subsubsection{QTL analysis method}

Two methods are often applied in QTL analyses. One is linear regression and the other is maximum likelihood (ML). The former is easy to extend the linear regression 
model and requires few computing time, so it can fix more factors into the model and consider more models (Haley and Knott 1992; Haley et al., 1994). The latter uses the full information from the marker-trait distribution, so it is considered more powerful, but it need more computing time (Lander and Botstein, 1989; Jansen and Stam, 1994).

\subsubsection{Linear regression}

The linear regression method has been widely used in QTL mapping (Nii et al., 2005; Nii et al., 2006; Reiner et al., 2007; Edwards et al., 2008). This method includes the following four steps.

Firstly, determine the fixed effects and the covariates of the regression models. To enhance the power of the QTL analysis, the fixed effects and covariates should be included into the model to reduce the residual variance.

Secondly, infer the coefficients of the additive, the dominance and/or the imprinting effects at a given point based on the information of flanking markers (Haley and Knott, 1992; Haley et al., 1994).

Thirdly, regress these coefficients to the phenotype and estimate the effects of additive, dominance and/or imprinting. Comparing the model with QTL (full model) to the model without QTL (reduce model), if the full model is significantly better than the reduce model, the analysis point probably exists a QTL. In a linkage group, it might be that many test statistics exist that are greater than the threshold value, but only the analysis point with the maximum test statistics is considered as the position of the QTL.

Finally, determine whether the QTL effects exist. It exists if the effect of the QTL is significantly greater than zero. Usually, if the estimate of the effect is more than two times of its standard error, the effect is considered to exist.

\subsubsection{Maximum likelihood}

The maximum likelihood (ML) method had been popular in the QTL mapping in the past (Lander and Botstein, 1989; Jansen and Stam, 1994; Jansen, 1996). But now 
it is gradually replaced by the linear regression method.

If there exists a QTL linkage with a marker $M$ (the alternative hypothesis), assuming that the phenotypes of all individuals with QTL genotype $Q_{k}$ follow a normal distribution with mean of $\mu_{Q_{k}}$ and variance of $\sigma^{2}$, then the likelihood for an individual with phenotypic value $z$ and marker genotype $M_{\mathrm{j}}$ at an analysis point is

$$
l\left(z \mid M_{j}\right)=\sum_{k=1}^{N} \varphi\left(z, \mu_{Q_{k}}, \sigma^{2}\right) \operatorname{Pr}\left(Q_{k} \mid M_{j}\right)
$$

where $\varphi\left(z, \mu_{Q_{k}}, \sigma^{2}\right)$ is the density function for a normal distribution with mean of $\mu_{Q_{k}}$ and variance of $\sigma^{2}$, and $N$ is the number of genotype of the QTL. The $\operatorname{Pr}\left(Q_{k} \mid M_{\mathrm{j}}\right)$ are the probability of $Q_{k}$ given the marker genotype $M_{j}$, and can be calculated provided the genetic map and the genotypes of the markers. The overall likelihood for $n \mathrm{~F}_{2}$ individuals at the analysis point is the product of the individual likelihoods,

$$
l(z)=\prod_{i=1}^{n} l\left(z_{i} \mid M_{i}\right)
$$

where $n$ is the number of $\mathrm{F}_{2}$ individuals, $l\left(z_{i} \mid M_{i}\right)$ is the likelihood of the $i$ th individual.

If there doesn't exist a QTL linkage with the markers (the null hypothesis), assuming that the phenotypes of all individuals follow a normal distribution with mean of $\mu$ and variance of $\sigma^{2}$, then the likelihood for an individual with phenotypic value $z$ becomes

$$
l_{N}\left(z \mid M_{j}\right)=\varphi\left(z, \mu, \sigma^{2}\right)
$$

The overall likelihood for $n \mathrm{~F}_{2}$ individuals is the product of the individual likelihoods,

$$
l_{N}(z)=\prod_{i=1}^{n} l_{N}\left(z_{i} \mid M_{i}\right)
$$

where $n$ is the number of $F_{2}$ individuals, $l_{N}\left(z_{i} \mid M_{i}\right)$ is the likelihood of the $i$ th individual.

After the ML estimation under the null hypothesis and the alternative hypothesis, the likelihood ratio (LR) statistic can be used to test whether a QTL locates at the analysis point. The LR can be obtained from the MLs according to the following 
equation,

$$
L R=-2 \ln \left[\frac{\operatorname{Max} l_{N}(z)}{\operatorname{Max} l(z)}\right]
$$

The likelihood ratio follows an approximate chi-square distribution with the degrees of freedom equal to the extra number of parameters fitted in the alternative hypothesis model.

\subsubsection{Threshold value}

There are a lot of analysis points in the QTL analysis. Each point needs a test, so a large number of tests are performed. Some of them are independent, but the others are not. In order to control false positive results arising from the multiple comparisons, a Bonferroni correction or a permutation approach is often used to adjust the threshold values (Churchill and Doerge, 1994; de Koning et al., 2001).

\subsubsection{Significant level}

Four significant levels are widely applied in QTL mapping studies: 5\% and 1\% chromosome-wide and $5 \%$ and $1 \%$ genome-wide significant levels. When scanning QTL on a part of the chromosomes, the $5 \%$ and $1 \%$ chromosome-wide significant levels are often used. While identifying QTL across the whole genome, the 5\% and $1 \%$ genome-wide significant levels are applied, and the average 5\% chromosome-wide threshold is often considered as the suggestive significance level. The $5 \%$ and $1 \%$ genome-wide threshold values can be obtained directly from genome-wide permutation, and the suggestive threshold value is obtained from the formula: $P_{\text {Genome-wide }}=1-\left(1-P_{\text {Chromosome-wide }}\right)^{1 / r}$, where $r$ is the proportion of total genome length attributed to the chromosome (de Koning et al., 2001). 


\subsubsection{Bonferroni correction}

The Bonferroni correction can be used for multiple dependent tests. Provided that an entire significant level $\gamma$ is set for the whole experiment with $n$ dependent tests, an overall significance level $\gamma$ requires each individual test based on a significant level of $\alpha=1-(1-\gamma)^{\frac{1}{n}}$. In QTL analyses, some tests are independent, but the others are not. The number of dependent tests is difficult to obtained, so the Bonferroni correction is not often used in QTL mapping (Lynch and Walsh, 1998).

\subsubsection{Permutation approach}

A more robust method to obtain overall significant threshold value is a permutation approach proposed by Churchill and Doerge (1994). The principle of the method is to generate an empirical distribution of the test statistic under the null hypothesis. Significance thresholds can be determined based on the empirical distribution (Churchill and Doerge, 1994; Doerge and Churchill, 1996). To produce a population under null hypothesis with the original data, the association between the phenotype and the genotype must be removed by randomly reassigning the phenotypic values. Iterating $n$ times of the reassignment procedure will generate $n$ populations. The values of the test statistic from these populations will give an empirical distribution under the null hypothesis. When $n$ is big enough, the empirical distribution of test statistics will be approximate to the true distribution of the test statistic.

\subsubsection{5\% confidence interval}

The location with the maximum value of the test statistic is the point estimate of the QTL position, and the $95 \%$ confidence interval $\left(\mathrm{CI}_{0.95}\right)$ is the interval estimate of the QTL position. In QTL mapping, the interval estimate is more important than the 
point estimate, because it point out the direction of the study following the QTL study. If the $\mathrm{CI}_{0.95}$ is large, a QTL fine mapping is required to narrow it. If it is small enough, the positional cloning or positional candidate gene approach can be followed to dissect the causative gene(s) and mutation(s). There are two ways to construct the $\mathrm{CI}_{0.95}$ (Lander and Botstein, 1989; Visscher et al., 1996).

\subsubsection{One-LOD rule}

The $\mathrm{CI}_{0.95}$ comprises all of locations of which the logarithm of odds (LOD score) are greater than the maximum LOD score minus one. In a large sample, the statistic of likelihood ratio (LR) follows a chi-square distribution. Dropping one LOD score is equal to the LR decrement of 4.61, which corresponds to $P=0.0318$ for a chi-square distribution with one degree of freedom. So if the degree of freedom of LR statistic is one, one-LOD support interval approximates the $\mathrm{CI}_{0.95}$ (Conneally et al., 1985; Lander and Botstein, 1989). But in most of QTL mapping studies, the degree of freedom is more than one, so the one-LOD support interval constructs an unconservative confidence interval. Thus, some researchers proposed that a 1.5 or 2-LOD support interval may be a better choice (van Ooijen, 1992; Mangin et al., 1994). When the ML method is used to do the QTL analysis, the bootstrap approach is not suitable to set up the $\mathrm{CI}_{0.95}$ due to its requirement of computer time, so the one-LOD rule is often used to construct the $\mathrm{CI}_{0.95}$ (Lander and Botstein, 1989).

\subsubsection{Bootstrap approach}

The bootstrap approach is one kind of re-sampling method and a very robust and popular procedure for constructing the $\mathrm{CI}_{0.95}$ of a QTL position (Visscher et al., 1996). Suppose that the original data contain $n$ individuals, a bootstrap sample is generated by drawing $n$ individuals out of the original data with replacement. So a bootstrap sample contains some of the original values presenting multiple times and some are not present at all. When $N$ times of such samples have been drawn, the empirical distribution of the position can be constructed. The $\mathrm{CI}_{0.95}$ can easily be determined on 
the base of the empirical distribution.

\subsubsection{Joint analysis}

In most cases, data from different studies were analyzed separately (Andersson et al., 1994; Rothschild et al., 1995; Knott et al., 1998), but in principle, the data can be put together to perform a more powerful combined analysis (Lander and Kruglyak, 1995). Until now, only few combined QTL studies have been reported in farm animals (Walling et al., 1998; Walling et al., 2000; Bennewitz et al., 2003; Lee et al., 2003; Kim et al., 2005).

\subsubsection{The advantage and the disadvantage of a joint analysis}

A joint analysis can increase the power to detect QTL or confirm the QTL detected only in one population, and improve the accuracy with which QTL parameters are estimated, especially when population sizes were small (Lander and Kruglyak, 1995). Combined analyses also permit testing more highly parameterized or complicated models.

In the other hand, joint analyses also encounter some problems. Different populations will have different founder animals, potentially not from the same breeds, so the QTL genotypes are probably not common in these populations. Furthermore, each population is often reared in a different location, and the traits will be measured with different testing regimes. The genotyped markers are often not the same set across the populations.

Some methods have been proposed to solve these discordant problems among the populations (Walling et al., 1998; Walling et al., 2000; Bennewitz et al., 2003; Lee et al., 2003; Kim et al., 2005). Firstly, take the population as a fixed effect in the QTL analysis model to correct the environmental effect. Secondly, test the interaction between the QTL and the population. If the interaction is significant, then the QTL probably just exists in a subset of the populations; otherwise the QTL has different 
effects in different populations. Thirdly, the phenotypes from each population are separately standardized to a mean of zero and variance of one. The standardization can get rid of the effect of the different testing regimes. Finally, use all of the genotyped markers in the populations; it can make the markers cover the genome as widely as possible.

\subsubsection{Advance of joint analysis in pigs}

Three joint analyses have been reported for specific chromosomes in pigs (Walling et al., 2000; Kim et al., 2005; Perez-Enciso et al., 2005). Walling et al. (2000) collected data from almost 3,000 pigs in seven $F_{2}$ crosses between Western commercial breeds and either the European wild boar or the Chinese Meishan breed, and scanned chromosome 4 for birth weight, average backfat depth and growth rate from birth to slaughter or end of test. A QTL influencing birth weight found in one population was confirmed by the joint analysis. Kim et al. (2005) combined the data from a Berkshire $\times$ Yorkshire $F_{2}$ population and a Berkshire $\times$ Duroc $F_{2}$ population, and scanned chromosomes 2, 6, 13 and 18 for 26 traits. The results suggested that the combined analysis using a range of QTL models increased the power of QTL mapping. Pérez-Enciso et al. (2005) demonstrated the advantages of a multibreed analysis for analysing the $\mathrm{X}$ chromosome with data from five different crosses.

\subsubsection{Computer software and program}

Ordinary linear regression can be performed with commercial statistic packages, such as Statistics Analysis System (SAS) and Statistical Package for the Social Science (SSPS), but calculation of the coefficients of the additive and the dominance effects in the QTL analysis is required special programs. For ML, it also requires special programs to calculate the probability of each QTL genotype. There are many programs written for QTL analysis. Some of them can be download freely from http://linkage.rockefeller.edu/soft/, such as MAPMAKER/QTL (Lander and 
Botstein, 1989) and MAPQTL (van Ooijen and Maliepaard, 1996). And some can be used online without charge, such as QTL Express at http://qtl.cap.ed.ac.uk/ (Seaton et al., 2002) and GridQTL at http://www.gridqtl.org.uk/ (Seaton et al., 2006).

\subsubsection{QTL Express}

QTL Express is a free online program (http://qtl.cap.ed.ac.uk/), which is widely used in the QTL analysis in pigs (Seaton et al., 2002). The statistical approach adopted for QTL analysis in QTL Express is developed by Haley et al. (1994). It is a linear regression method as described above. For a cross between outbred lines, it is based on the assumption that the QTL is fixed for alternative alleles in the two founder breeds.

A positive value of the additive effect means that the allele from first line associates with the high numerical value of the trait. Both the dominance and the additive effects are positive or negative, the allele from the first line is dominant; otherwise the allele from second line is dominant. When both the additive and the imprinting effects are positive or negative, the paternal allele expresses; otherwise the maternal allele expresses.

\subsection{Leg weakness}

Leg weakness is used to describe a poor leg conformation or a clinical condition associated with lameness and stiffness. Leg weakness may occur in any leg at all ages and sexes of pigs. Leg weakness does not affect the daily gain or food conversion efficiency. However, it can restrict the sale and the utility of breeding boars and gilts. Leg weakness increases involuntary culling and results in huge economic loss. It makes $20-50 \%$ of otherwise eligible boars completing a performance test to be rejected as breeding animals (Webb et al., 1983; Sternbergen, 1989). Genetic 
correlations between leg weakness and stayability of breeding sows suggest that a better leg status would decrease involuntary culling (Lopez-Serrano et al., 2000).

\subsubsection{The factors causing leg weakness}

There are many factors resulting in leg weakness in pigs, such as poor leg conformations, bone and joint diseases, nutritional imbalances or deficiencies, hereditary component, space available for exercise and others (Rothschild and Christian, 1988; Lee et al., 2003).

\subsubsection{Poor leg conformation}

Leg conformation is definitely the primary determinant of leg weakness. Structures causing leg weakness in pigs include buckling of the knees, bowed legs, splayed legs, uneven toe size, pigeon toes and sickle hocks. A pig with weak legs tends to have straight front and/or rear legs, resulting in an arched back, short strides and unwillingness to move. In comparison, a pig with sound legs usually has a flatter top and higher tail setting.

\subsubsection{Bone and joint disease}

Osteochondrosis, arthritis and osteoporosis are the three most common bone diseases, and also the major underlying causes of leg weakness in pigs (Grondalen, 1974; Hill, 1990a, b; Jorgensen et al., 1995; Jørgensen and Andersen, 2000).

Osteochondrosis, also called epiphyseal ischemic necrosis, is relatively common temporary orthopedic disorder, in which the epiphysis (growing end) of a bone dies and then is gradually replaced over a period of years. The immediate cause of bone death is loss of blood supply, so the bone cannot obtain the necessary nutrients for maintaining and endochondral ossification. Osteochondrosis usually occurs in rapidly growing pigs, especially when the growing pigs do not ingest enough of the essential 
trace element boron.

Arthritis literally means inflammation of one or more joints. It is a kind of joint disorder characterized by joint stiffness, swelling, redness, and warmth. Arthritis is frequently accompanied by joint pain and limited function of joints, and serious arthritis lead pigs to lose their movement. The causes of arthritis are injury, normal wear and tear, or disease.

Osteoporosis is a silent and painless disease, in which bones lose their normal density and become fragile and more likely to break. Osteoporosis leads to abnormally porous bone that is more compressible like a sponge than dense like a brick. This disorder of the skeleton weakens the bone, leading to an increase of the risk of breaking bones. Fractures, can occur in almost any skeletal bone area, but more often happen in the hip, spine and wrist. Bones that are affected by osteoporosis can fracture with only a minor fall or injury that normally would not cause a bone fracture. The bone mineral density test is the best way to check osteoporosis.

\subsubsection{Nutritional deficiencies}

Normal bones are composed mainly of protein, collagen and calcium. If the intake quantities of these materials are less than the body requires, the bone will be absorbed and osteoporosis will occur. To keep bones strong, the diet must be rich in calcium, protein and vitamin D. Vitamin D significantly improves the absorption of calcium. As mentioned above, the deficiency of the essential trace element boron in rapidly growing pigs will also cause osteochondrosis.

\subsubsection{Space available for exercise}

Appropriate exercise can improve leg soundness of pigs. But the space for pig exercise become limited with the modern confinement rearing systems widely applied in swine industry. The confinement rearing system deprives the possibility for exercise and fuels the prevalence of leg weakness. 


\subsubsection{Genetics}

Many reports have supported a hereditary component determining leg weakness, and the heritability of leg weakness is estimated from low to moderate (Reiland et al., 1978; Bereskin, 1979; Webb et al., 1983; Rothschild and Christian, 1988). A divergent selection experiment for leg weakness also proved that the leg weakness was determined by heredity. After five-generation selection, a line with sound legs and a line with weak legs had been developed (Rothschild and Christian, 1988).

\subsubsection{Methods to assess leg weakness}

Leg weakness can be assessed in three ways: leg score (LS), gait score (GS) and bone mineral density (BMD).

\subsubsection{Leg score and gait score}

Leg score is used to assess the weakness of the leg conformation and gait score is employed to record the smoothness of the legs' movement. There are two systems to score the leg conformation and the movement as supposed by Rothschild and Christian (1988) and Lee et al. (2003), respectively. The first system scores the structure and the movement of the front legs, and the latter assess the structure and the gait of both front legs and rear legs.

Leg score is determined according to the strength of the leg, buckling of the knees, even toe size and the damage and angles of the joints (shoulder angle for front leg and stifle angle for rear leg). Gait score assesses the speed of walking, the ease and the smoothness of leg movement and the steadiness of the body, especially the hindquarters while walking (Rothschild and Christian, 1988; Lee et al., 2003). The desirable and undesirable shoulder and stifle angles are shown in Figure 2. The smaller the angles, the more sound the legs are. 



Figure 2 The desirable and the undesirable shoulder and stifle angles in pigs.

(Cited from http://www.thepigsite.cn/pighealth/article/189/leg-weakness with slight modification)

\subsubsection{Bone mineral density}

Bone mineral density is a major determinant of risk for osteoporosis and bone fractures, and BMD screening can be applied in the fracture risk assessment in the pig industry (Dequeker et al., 1987; Melton et al., 1989; Nielsen et al., 2007). With the advance of technologies and the application of new equipments, dual energy X-ray absorptiometry (DXA) can measure BMD accurately, precisely and reliably (Mitchell et al., 2000, 2001; Fink et al., 2002). Bone mineral density scanning works by measuring the amount of X-rays that are absorbed by the bones. The bone with more mineral density absorbs more X-rays. The two X-ray energies can differentiate the bone density from the soft tissue density, giving a more accurate estimation of BMD.

\subsubsection{The known QTL for leg weakness related traits in pigs}

To dissect the genes controlling the leg weakness in pigs, genome-wide scanning 
for the loci affecting leg weakness and its related traits has been performed. The identified QTL significantly affecting leg weakness and their related traits in different populations are listed in Table 1 (Andersson-Eklund et al., 2000; Lee et al., 2003).

Table 1 QTL for leg weakness and their related traits in different populations

\begin{tabular}{|c|c|c|c|}
\hline Trait $^{a}$ & Population & Chromosome $^{b}$ & Favorable allele \\
\hline Osteochondrosis & Wild boar $\times$ Large White & SSC5 & Wild boar \\
\hline Osteochondrosis & Wild boar $\times$ Large White & SSC13 & Wild boar \\
\hline Gait score & Large White $\times$ Meishan & SSC1 & Large White \\
\hline Back legs score & Large White $\times$ Meishan & $\mathrm{SSC} 1$ & Large White \\
\hline Front feet score & Large White $\times$ Meishan & $\mathrm{SSC} 1$ & Large White \\
\hline Gait score & Large White $\times$ Meishan & $\mathrm{SSC} 2$ & Meishan \\
\hline Back legs score & Large White $\times$ Meishan & SSC3 & Large White \\
\hline Gait score & Large White $\times$ Meishan & SSC4 & Large White \\
\hline Gait score & Large White $\times$ Meishan & SSC5 & Meishan \\
\hline Physis score & Large White $\times$ Meishan & SSC7 & Meishan \\
\hline Gait score & Large White $\times$ Meishan & $\mathrm{SSC} 10$ & Large White \\
\hline Front feet score & Large White $\times$ Meishan & SSC13 & Meishan \\
\hline Front legs score & Large White $\times$ Meishan & SSC13 & Large White \\
\hline Front feet score & Large White $\times$ Meishan & $\mathrm{SSC} 14$ & Meishan \\
\hline Front legs score & Large White $\times$ Meishan & SSC14 & Large White \\
\hline Back legs score & Large White $\times$ Meishan & SSC14 & Large White \\
\hline Back feet score & Large White $\times$ Meishan & SSC15 & Large White \\
\hline
\end{tabular}

a . The QTL for osteochondrosis were reported by Andersson-Eklund et al. (2000) and the rest were identified by Lee et al (2003); ${ }^{b}$. Bold and regular fonts indicate the QTL reaching 5\% genome-wide and suggestive significant level, respectively. 


\subsection{Limb bones and biceps brachii muscle}

Limb bones and the biceps brachii muscle are related with the function of legs. Moderate lengths of limb bones combined with appropriate body length will improve leg soundness of pigs (Wood, 2001). Pigs from leg soundness lines have shorter and lighter biceps brachii muscles than those from leg weakness lines (Draper et al., 1991).

\subsubsection{Limb bones}

The lengths of limb bones are generally regarded as a very important parameter to assess the bone growth in pigs, and the growth of limb bones will affect the leg soundness. Dissection of the genes controlling the growth of limb bones in pigs will shed light on the genetics of the leg weakness in pigs.

\subsubsection{The relationship between limb bone length and other traits}

An individual with long limb bones usually has a tall body height or a tall height at shoulder. Previous studies indicate that the height at shoulder is an important parameter in determining the yield of some carcass characteristics in pigs, such as the yield of ham, loin, picnic shoulder and shoulder butt (Hetzer et al., 1950; Hetzer and Miller, 1972). It has been shown that visual selection for moderate length of the leg combined with appropriate body length in boars and gilts can improve structural soundness and decrease the economic loss resulting from structural unsoundness for producers (Wood, 2001).

\subsubsection{Bone growth}

Longitudinal growth of the skeleton occurs through the action of chondrocytes in the proliferative and hypertrophic zones of the growth plate (Karsenty and Wagner, 
2002). A long bone, such as the femur (thigh bone), grows in length at both ends in regions called epiphyseal plates (growth plates). Growth occurs when cartilage cells divide and increase in number in these growth plates. When cartilage cells become older, they will change into larger cartilage cells and will be towards the middle of a bone. Finally, these older cartilage cells die and the space they occupied is replaced with bone. Long bone growth comes to an end around the end of puberty, at that time the growth plates of bone are completely ossified.

Bone growth is under the influence of the intake quantity of protein, calcium and vitamin D. Deficiency of these nutriments will impede the growth of bone. Some other growth factors are also required for bone growth (Mitchell et al., 2001). Furthermore, bone growth is regulated by growth hormone from the anterior pituitary gland and sex hormones from ovaries or testes.

\subsubsection{Advance of QTL mapping for limb bone length}

To my knowledge, so far, just one QTL study on limb bone length has been reported in pigs. Only one 5\% genome-wide QTL and three suggestive QTL for femur dimensions were detected in pigs, which are located on SSC17, SSC2, SSC4 and SSC16, respectively (Andersson-Eklund et al., 2000).

\subsubsection{Biceps brachii muscle}

Biceps brachii muscle, as an important movement muscle, affects the front leg soundness. It was reported that both the weight and the length of biceps brachii muscle were significantly greater in leg weakness lines than in normal and leg soundness lines (Draper et al., 1991). No QTL study of biceps brachii muscle has been reported until now. 


\subsubsection{Types of muscle}

There are three types of muscle (skeletal, cardiac and smooth muscle) in animals. Skeletal muscle is striated and voluntary; cardiac muscle is striated and involuntary; smooth muscle is non striated and involuntary. Skeletal muscles are attached to the bones through tendons, and their contraction gives rise to the body's movement. Biceps brachii muscle is a tubular skeletal muscle located in the front legs, and its weight and length will affect the function of front legs.

\subsubsection{Relationship between the weight and the length of brachial muscle and leg weakness}

Both the weight and length of biceps brachii muscle are significantly greater $(P$ $<0.05$ and $P<0.01$, respectively) in leg weakness than in normal or leg soundness lines. But the weights and lengths of other brachial muscles show no differences between these lines except for the tensor fascia antibrachii, which is significantly longer $(P<0.01)$ in the leg weakness than in normal or soundness lines (Draper et al., 1991). Biceps brachii muscle is the most important brachial muscle that affects the front leg soundness. With the increase of the weight and length of biceps brachii muscle the front legs become weaker.

\subsection{References}

Andersson-Eklund L., Uhlhorn H., Lundeheim N., Dalin G. and Andersson L. (2000) Mapping quantitative trait loci for principal components of bone measurements and osteochondrosis scores in a wild boar $\times$ large white intercross. Genet Res 75, 223-30.

Andersson L., Haley C.S., Ellegren H., Knott S.A., Johansson M., Andersson K., 
Andersson-Eklund L., Edfors-Lilja I., Fredholm M., Hansson I., Håkansson J. and Lundström K. (1994) Genetic mapping of quantitative trait loci for growth and fatness in pigs. Science 263, 1771-4.

Andersson L. and Sandberg K. (1984) Genetic linkage in the horse. II. Distribution of male recombination estimates and the influence of age, breed and sex on recombination frequency. Genetics 106, 109-22.

Archibald A.L., Brown J.F., Haley C.S., Fredholm M., Wintero A.K., Coppieters W., Van de Weghe A., Signer E., Larsen N.J., Nielsen V.H., Johansson M. and Andersson L. (1992) Linkage mapping in the domestic pig (Sus scrofa). Anim Genet 23, 88 .

Archibald A.L., Haley C.S., Brown J.F., Couperwhite S., McQueen H.A., Nicholson D., Coppieters W., Van de Weghe A., Stratil A., Winterø A.K., Fredholm M., Larsen N.J., Nielsen V.H., Milan D., Woloszyn N., Robic A., Dalens M., Riquet J., Gellin J., Caritez J.-C., Burgaud G., Ollivier L., Bidanel J.-P., Vaiman M., Renard C., Geldermann H., Davoli R., Ruyter D., Verstege E.J.M., Groenen M.A.M., Davies W., Høyheim B., Keiserud A., Andersson L., Ellegren H., Johansson M., Marklund L., Miller J.R., Anderson Dear D.V., Signer E., Jeffreys A.J., Moran C., Le Tissier P., Muladno, Rothschild M.F., Tuggle C.K., Vaske D., Helm J., Liu H.-C., Rahman A., Yu T.-P., Larson R.G. and Schmitz C.B. (1995) The PiGMaP consortium linkage map of the pig (Sus scrofa). Mamm Genome 6, 157-75.

Balint-Kurti P.J., Zwonitzer J.C., Wisser R.J., Carson M.L., Oropeza-Rosas M.A., Holland J.B. and Szalma S.J. (2007) Precise mapping of quantitative trait loci for resistance to southern leaf blight, caused by Cochliobolus heterostrophus race $\mathrm{O}$, and flowering time using advanced intercross maize lines. Genetics 176, 645-57.

Bennewitz J., Reinsch N., Grohs C., Leveziel H., Malafosse A., Thomsen H., Xu N., Looft C., Kuhn C., Brockmann G.A., Schwerin M., Weimann C., Hiendleder S., Erhardt G., Medjugorac I., Russ I., Forster M., Brenig B., Reinhardt F., Reents R., Averdunk G., Blumel J., Boichard D. and Kalm E. (2003) 
Combined analysis of data from two granddaughter designs: A simple strategy for QTL confirmation and increasing experimental power in dairy cattle. Genet Sel Evol 35, 319-38.

Bereskin B. (1979) Genetic aspects of feet and leg soundness in swine. J Anim Sci 48 , 1322-28.

Bridges C.B. (1915) A linkage variation in Drosophila. J. Exp. Zool. 19, 1-21.

Broman K.W., Murray J.C., Sheffield V.C., White R.L. and Weber J.L. (1998) Comprehensive human genetic maps: individual and sex-specific variation in recombination. Am J Hum Genet 63, 861-9.

Burt A. and Bell G. (1987) Mammalian chiasma frequencies as a test of two theories of recombination. Nature 326, 803-5.

Callan H.G. and Perry P.E. (1977) Recombination in male and female meiocytes contrasted. Philos Trans R Soc Lond B Biol Sci 277, 227-33.

Churchill G.A. and Doerge R.W. (1994) Empirical threshold values for quantitative trait mapping. Genetics 138, 963-71.

Conneally P.M., Edwards J.H., Kidd K.K., Lalouel J.M., Morton N.E., Ott J. and White R. (1985) Report of the Committee on Methods of Linkage Analysis and Reporting. Cytogenet Cell Genet 40, 356-9.

Darvasi A. and Soller M. (1995) Advanced intercross lines, an experimental population for fine genetic mapping. Genetics 141, 1199-207.

de Koning D.J., Harlizius B., Rattink A.P., Groenen M.A., Brascamp E.W. and van Arendonk J.A. (2001) Detection and characterization of quantitative trait loci for meat quality traits in pigs. J Anim Sci 79, 2812-9.

Dequeker J., Nijs J., Verstraeten A., Geusens P. and Gevers G. (1987) Genetic determinants of bone mineral content at the spine and radius: a twin study. Bone 8, 207-9.

Doerge R.W. and Churchill G.A. (1996) Permutation tests for multiple loci affecting a quantitative character. Genetics 142, 285-94.

Draper D.D., Rothschild M.F. and Christian L.L. (1991) Effects of Divergent Selection for Limb Weakness on Bone and Muscle Cross-Sectional Areas in 
Duroc Swine. American Journal of Veterinary Research 52, 164-68.

Dunn L.C. and Bennett D. (1967) Sex differences in recombination of linked genes in animals. Genet Res 9, 211-20.

Edwards D.B., Ernst C.W., Tempelman R.J., Rosa G.J., Raney N.E., Hoge M.D. and Bates R.O. (2008) Quantitative trait loci mapping in an $F_{2}$ Duroc $\times$ Pietrain resource population: I. Growth traits. J Anim Sci 86, 241-53.

Ellegren H., Chowdhary B.P., Johansson M., Marklund L., Fredholm M., Gustavsson I. and Andersson L. (1994) A primary linkage map of the porcine genome reveals a low rate of genetic recombination. Genetics 137, 1089-100.

Elston R.C., Lange E. and Namboodiri K.K. (1976) Age trends in human chiasma frequencies and recombination fractions. II. Method for analyzing recombination fractions and applications to the ABO: nail-patella linkage. $\mathrm{Am}$ J Hum Genet 28, 69-76.

Fink C., Cooper H.J., Huebner J.L., Guilak F. and Kraus V.B. (2002) Precision and accuracy of a transportable dual-energy X-ray absorptiometry unit for bone mineral measurements in guinea pigs. Calcif Tissue Int 70, 164-9.

Groenen M.A., Crooijmans R.P., Veenendaal A., Cheng H.H., Siwek M. and van der Poel J.J. (1998) A comprehensive microsatellite linkage map of the chicken genome. Genomics 49, 265-74.

Grondalen T. (1974) Osteochondrosis, arthrosis and leg weakness in pigs. Nord Vet Med 26, 534-7.

Grushko T.A., Korochkina S.E. and Klimenko V.V. (1991) Temperature control of the crossing-over frequency in Drosophila melanogaster. Effect of infra- and super-optimal shock temperatures in early ontogenesis on the recombination frequency. Genetika 27, 1714-21.

Haley C.S. and Knott S.A. (1992) A simple regression method for mapping quantitative trait loci in line crosses using flanking markers. Heredity 69, 315-24.

Haley C.S., Knott S.A. and Elsen J.M. (1994) Mapping quantitative trait loci in crosses between outbred lines using least squares. Genetics 136, 1195-207. 
Hetzer H.O., Hankins O.G., King J.X. and Zeller J.H. (1950) Relationship between certain body measurements and carcass characteristics in swine. J Anim Sci 9, $37-47$.

Hetzer H.O. and Miller R.H. (1972) Correlated responses of various body measurements in swine selected for high and low fatness. J Anim Sci 35, 743-51.

Heyen D.W., Weller J.I., Ron M., Band M., Beever J.E., Feldmesser E., Da Y., Wiggans G.R., VanRaden P.M. and Lewin H.A. (1999) A genome scan for QTL influencing milk production and health traits in dairy cattle. Physiol Genomics 1, 165-75.

Hill M.A. (1990a) Causes of degenerative joint disease (osteoarthrosis) and dyschondroplasia (osteochondrosis) in pigs. J Am Vet Med Assoc 197, 107-13.

Hill M.A. (1990b) Economic relevance, diagnosis, and countermeasures for degenerative joint disease (osteoarthrosis) and dyschondroplasia (osteochondrosis) in pigs. $J$ Am Vet Med Assoc 197, 254-9.

Iraqi F. (2000) Fine mapping of quantitative trait loci using advanced intercross lines of mice and positional cloning of the corresponding genes. Exp Lung Res 26, 641-9.

Iraqi F., Clapcott S.J., Kumari P., Haley C.S., Kemp S.J. and Teale A.J. (2000) Fine mapping of trypanosomiasis resistance loci in murine advanced intercross lines. Mamm Genome 11, 645-8.

Jørgensen B. and Andersen S. (2000) Genetic parameters for osteochondrosis in Danish Landrace and Yorkshire boars and correlations with leg weakness and production traits. Animal Science 71, 427-34.

Jansen R.C. (1996) A general Monte Carlo method for mapping multiple quantitative trait loci. Genetics 142, 305-11.

Jansen R.C. and Stam P. (1994) High resolution of quantitative traits into multiple loci via interval mapping. Genetics 136, 1447-55.

Jorgensen B., Arnbjerg J. and Aaslyng M. (1995) Pathological and radiological investigations on osteochondrosis in pigs, associated with leg weakness. 
Zentralbl Veterinarmed A 42, 489-504.

Karsenty G. and Wagner E.F. (2002) Reaching a genetic and molecular understanding of skeletal development. Dev Cell 2, 389-406.

Kim J.J., Rothschild M.F., Beever J., Rodriguez-Zas S. and Dekkers J.C. (2005) Joint analysis of two breed cross populations in pigs to improve detection and characterization of quantitative trait loci. J Anim Sci 83, 1229-40.

Knott S.A., Marklund L., Haley C.S., Andersson K., Davies W., Ellegren H., Fredholm M., Hansson I., Hoyheim B., Lundstrom K., Moller M. and Andersson L. (1998) Multiple marker mapping of quantitative trait loci in a cross between outbred wild boar and large white pigs. Genetics 149, 1069-80.

Lander E. and Kruglyak L. (1995) Genetic dissection of complex traits: guidelines for interpreting and reporting linkage results. Nat Genet 11, 241-7.

Lander E.S. and Botstein D. (1989) Mapping mendelian factors underlying quantitative traits using RFLP linkage maps. Genetics 121, 185-99.

Lange K., Page B.M. and Elston R.C. (1975) Age trends in human chiasma frequencies and recombination fractions. I. Chiasma frequencies. Am J Hum Genet 27, 410-8.

Lee G.J., Archibald A.L., Garth G.B., Law A.S., Nicholson D., Barr A. and Haley C.S. (2003) Detection of quantitative trait loci for locomotion and osteochondrosis related traits in Large White $\times$ Meishan pigs. Anim Sci 76, 155-65.

Lopez-Serrano M., Reinsch N., Looft H. and Kalm E. (2000) Genetic correlations of growth, backfat thickness and exterior with stayability in Large White and Landrace sows. Livest Prod Sci 64, 121-31.

Lu B.C. (1974) Genetic Recombination in Coprinus. IV. a Kinetic Study of the Temperature Effect on Recombination Frequency. Genetics 78, 661-77.

Lynch M. and Walsh B. (1998) Genetics and Analysis of Quantitative Traits. Sinauer Associates, Sunderland, MA.

Mangin B., Goffinet B. and Rebai A. (1994) Constructing confidence intervals for QTL location. Genetics 138, 1301-8.

Mariasegaram M., Robinson N.A. and Goddard M.E. (2007) Empirical evaluation of 
selective DNA pooling to map QTL in dairy cattle using a half-sib design by comparison to individual genotyping and interval mapping. Genet Sel Evol 39, 267-83.

Marklund L., Johansson Moller M., Hoyheim B., Davies W., Fredholm M., Juneja R.K., Mariani P., Coppieters W., Ellegren H. and Andersson L. (1996) A comprehensive linkage map of the pig based on a wild pig-Large White intercross. Anim Genet 27, 255-69.

Maynard Smith J. (1978) The evolution of sex. Cambridge University Press, Cambridge.

Melton L.J., 3rd, Kan S.H., Frye M.A., Wahner H.W., O'Fallon W.M. and Riggs B.L. (1989) Epidemiology of vertebral fractures in women. Am J Epidemiol 129, 1000-11.

Mikawa S., Akita T., Hisamatsu N., Inage Y., Ito Y., Kobayashi E., Kusumoto H., Matsumoto T., Mikami H., Minezawa M., Miyake M., Shimanuki S., Sugiyama C., Uchida Y., Wada Y., Yanai S. and Yasue H. (1999) A linkage map of 243 DNA markers in an intercross of Göttingen miniature and Meishan pigs. Anim Genet 30, 407-17.

Milan D., Jeon J.T., Looft C., Amarger V., Robic A., Thelander M., Rogel-Gaillard C., Paul S., Iannuccelli N., Rask L., Ronne H., Lundstrom K., Reinsch N., Gellin J., Kalm E., Roy P.L., Chardon P. and Andersson L. (2000) A mutation in PRKAG3 associated with excess glycogen content in pig skeletal muscle. Science 288, 1248-51.

Mitchell A.D., Scholz A.M. and Pursel V.G. (2000) Dual-energy X-ray absorptiometry measurements of the body composition of pigs of 90- to 130-kilograms body weight. Ann N Y Acad Sci 904, 85-93.

Mitchell A.D., Scholz A.M. and Pursel V.G. (2001) Total body and regional measurements of bone mineral content and bone mineral density in pigs by dual energy X-ray absorptiometry. J Anim Sci 79, 2594-604.

Morgan T.H., Bridges C.B. and Sturtevant A.H. (1925) The genetics of drosophila. Bibliogr. Genet. 2, 1-262. 
Neff M.W., Broman K.W., Mellersh C.S., Ray K., Acland G.M., Aguirre G.D., Ziegle J.S., Ostrander E.A. and Rine J. (1999) A second-generation genetic linkage map of the domestic dog, Canis familiaris. Genetics 151, 803-20.

Nielsen D.H., McEvoy F.J., Madsen M.T., Jensen J.B. and Svalastoga E. (2007) Relationship between bone strength and dual-energy X-ray absorptiometry measurements in pigs. $J$ Anim Sci 85, 667-72.

Nii M., Hayashi T., Mikawa S., Tani F., Niki A., Mori N., Uchida Y., Fujishima-Kanaya N., Komatsu M. and Awata T. (2005) Quantitative trait loci mapping for meat quality and muscle fiber traits in a Japanese wild boar $\mathrm{x}$ Large White intercross. J Anim Sci 83, 308-15.

Nii M., Hayashi T., Tani F., Niki A., Mori N., Fujishima-Kanaya N., Komatsu M., Aikawa K., Awata T. and Mikawa S. (2006) Quantitative trait loci mapping for fatty acid composition traits in perirenal and back fat using a Japanese wild boar x Large White intercross. Anim Genet 37, 342-7.

Perez-Enciso M., Mercade A., Bidanel J.P., Geldermann H., Cepica S., Bartenschlager H., Varona L., Milan D. and Folch J.M. (2005) Large-scale, multibreed, multitrait analyses of quantitative trait loci experiments: the case of porcine $\mathrm{X}$ chromosome. J Anim Sci 83, 2289-96.

Redfield H. (1966) Delayed mating and the relationship of recombination to maternal age in Drosophila melanogaster. Genetics 53, 593-607.

Reiland S., Ordell N., Lundeheim N. and Olsson S.E. (1978) Heredity of osteochondrosis, body constitution and leg weakness in the pig. A correlative investigation using progeny testing. Acta Radiol Suppl 358, 123-37.

Reiner G., Kliemt D., Willems H., Berge T., Fischer R., Kohler F., Hepp S., Hertrampf B., Daugschies A., Geldermann H., Mackenstedt U. and Zahner H. (2007) Mapping of quantitative trait loci affecting resistance/susceptibility to Sarcocystis miescheriana in swine. Genomics 89, 638-46.

Ren J., Guo Y.M., Ma J.W. and Huang L.S. (2006) Growth and meat quality QTL in pigs with special reference to a very large Erhualian $\times$ White Duroc resource population. In: 8th World Congress on Genetics Applied in Livestock 
Production, Brazil.

Renwick J.H. and Schulze J. (1965) Male and female recombination fractions for the nailpatella: ABO linkage in man. Ann. Hum. Genet. 28, 379-92.

Rohrer G.A., Alexander L.J., Hu Z., Smith T.P., Keele J.W. and Beattie C.W. (1996) A comprehensive map of the porcine genome. Genome Res 6, 371-91.

Rohrer G.A., Alexander L.J., Keele J.W., Smith T.P. and Beattie C.W. (1994) A microsatellite linkage map of the porcine genome. Genetics 136, 231-45.

Rohrer G.A., Thallman R.M., Shackelford S., Wheeler T. and Koohmaraie M. (2006) A genome scan for loci affecting pork quality in a Duroc-Landrace $\mathrm{F}$ population. Anim Genet 37, 17-27.

Rose A.M. and Baillie D.L. (1979) The Effect of Temperature and Parental Age on Recombination and Nondisjunction in Caenorhabditis Elegans. Genetics 92, 409-18.

Rothschild M.F. and Christian L.L. (1988) Genetic control of front-leg weakness in Duroc swine. I. Direct response to five generations of divergent selection. Livest Prod Sci 19, 459-71.

Rothschild M.F., Liu H.C., Tuggle C.K., Yu T.P. and Wang L. (1995) Analysis of pig chromosome 7 genetic markers for growth and carcass performance traits. $J$ Anim Breed Genet 112, 341-8.

Rothschild M.F. and Ruvinsky A. (1998) The Genetic of the Pig. CAB International, Oxon, UK.

Seaton G., Haley C.S., Knott S.A., Kearsey M. and Visscher P.M. (2002) QTL Express: mapping quantitative trait loci in simple and complex pedigrees. Bioinformatics 18, 339-40.

Seaton G., Hernandez J., Grunchec J.A., White I., Allen J., De Koning D.J., Wei W., Berry D., Haley C.S. and Knott S.A. (2006) GridQTL: A Grid Portal for QTL Mapping of Compute Intensive Datasets. Proceedings of the 8th World Congress on Genetics Applied to Livestock Production, August 13-18, 2006. Belo Horizonte, Brazil.

Simchen G. and Stamberg J. (1969) Fine and coarse controls of genetic recombination. 
Nature 222, 329-32.

Sternbergen E.J.v. (1989) Description and evaluation of a linear scoring system for exterior traits in pigs. Livest Prod Sci 23, 163-81.

van Ooijen J.W. (1992) Accuracy of mapping quantitative trait loci in autogamous species. Theor. Appl. Genet. 84, 803-11.

van Ooijen J.W. and Maliepaard C. (1996) MapQTL Version 3.0: Software for the Calculation of QTL Positions on Genetic Maps. Plant Genome IV (Abs.), p105.

Visscher P.M., Thompson R. and Haley C.S. (1996) Confidence intervals in QTL mapping by bootstrapping. Genetics 143, 1013-20.

Walling G.A., Archibald A.L., Cattermole J.A., Downing A.C., Finlayson H.A., Nicholson D., Visscher P.M., Walker C.A. and Haley C.S. (1998) Mapping of quantitative trait loci on porcine chromosome 4. Anim Genet 29, 415-24.

Walling G.A., Visscher P.M., Andersson L., Rothschild M.F., Wang L., Moser G., Groenen M.A., Bidanel J.P., Cepica S., Archibald A.L., Geldermann H., de Koning D.J., Milan D. and Haley C.S. (2000) Combined analyses of data from quantitative trait loci mapping studies. Chromosome 4 effects on porcine growth and fatness. Genetics 155, 1369-78.

Wang M., Lemon W.J., Liu G., Wang Y., Iraqi F.A., Malkinson A.M. and You M. (2003a) Fine mapping and identification of candidate pulmonary adenoma susceptibility 1 genes using advanced intercross lines. Cancer Res 63, 3317-24.

Wang X., Le Roy I., Nicodeme E., Li R., Wagner R., Petros C., Churchill G.A., Harris S., Darvasi A., Kirilovsky J., Roubertoux P.L. and Paigen B. (2003b) Using advanced intercross lines for high-resolution mapping of HDL cholesterol quantitative trait loci. Genome Res 13, 1654-64.

Webb A.J., Russell W.S. and Sales D.I. (1983) Genetics of leg weakness in performance-tested boars. Animal Production 36, 117-30.

Weitkamp L.R. (1973) Human autosomal linkage groups. In: Proceedings of the 4th International Congress on Human Genetics, pp. 445-60, Exerpta Medica 
International Congress Series.

Weitkamp L.R., van Rood J.J., Thorsby E., Bias W., Fotino M., Lawler S.D., Duausset J., Maryr W.R., Bodmer J., Ward F.E., Seignalet J., Payne R., Kissmeyer-Nielsen F., Gatti R.A., Sachs J.A. and Lamm L.U. (1973) The relation of parental sex and age to reombination in the HL-A system. Hum. Hered. 23, 197-205.

Wood C.M. (2001) Don't Ignore Feet and Leg Soundness in Pigs, Livestock Update. Animal \& Poultry Sciences, VA Tech.

Zetka M.C. and Rose A.M. (1995) Mutant rec-1 eliminates the meiotic pattern of crossing over in Caenorhabditis elegans. Genetics 141, 1339-49. 


\title{
2
}

\section{Quantitative trait loci for production traits in pigs:}

\section{a combined analysis of two Meishan $\times$ Large White populations}

\author{
Y.-M. Guo ${ }^{1,2,3}$, G. J. Lee ${ }^{1}$, A. L. Archibald ${ }^{1}$, C. S. Haley ${ }^{1}$
}

${ }^{1}$ Roslin Institute (Edinburgh), Roslin, Midlothian EH25 9PS, UK

${ }^{2}$ Key Laboratory for Animal Biotechnology of Jiangxi Province and the Ministry of Agriculture of China, Jiangxi Agricultural University, Nanchang 330045, China

3 Institute of Veterinary Medicine, Georg-August-University of Göttingen, Burckhardtweg 2, 37077 Göttingen, Germany

Animal Genetics 39(5): 486-495 


\section{3}

\section{A linkage map of the porcine genome from a large scale White Duroc $\times$ Erhualian resource population and evaluation of factors affecting recombination rates}

Yuanmei Guo ${ }^{1,2,3}$, Huirong Mao', Jun Ren ${ }^{1}$, Xueming Yan ${ }^{1}$, Yanyu Duan ${ }^{1}$, Guangcheng Yang ${ }^{1}$, Dongren Ren ${ }^{1}$, Zhiyan Zhang ${ }^{1}$, Bin Yang ${ }^{1}$, Jing Ouyang ${ }^{1}$, Bertram Brenig $^{3}$, Chris Haley ${ }^{2,4}$, Lusheng Huang ${ }^{1 \dagger}$

${ }^{1}$ Key Laboratory for Animal Biotechnology of Jiangxi Province and the Ministry of Agriculture of China, Jiangxi Agricultural University, Nanchang 330045, China

2 Roslin Institute and Royal (Dick) School of Veterinary Studies, University of Edinburgh, Roslin BioCentre, Roslin, Midlothian EH25 9PS, UK

3 Institute of Veterinary Medicine, Georg-August-University of Göttingen, Burckhardtweg 2, 37077 Göttingen, Germany

${ }^{4}$ MRC Human Genetics Unit, Western General Hospital, Crew Road, Edinburgh, EH4 $2 X U$

Animal Genetics 40(1): 47-52 


\section{4}

\section{A whole genome scanning for quantitative trait loci for leg weakness and its related traits in a large $F_{2}$ intercross population between White Duroc and Erhualian}

Y. M. Guo ${ }^{*} \dagger, \ddagger$, H. S. Ai ${ }^{*}$, J. Ren $^{*}$, G. J. Wang ${ }^{\#}$, Y. Wen ${ }^{*}$, H. R. Mao ${ }^{*}$ L. T. Lan ${ }^{*}$, J. W. Ma $^{*}$, B. Brenig ${ }^{\dagger}$, M. F. Rothschild ${ }^{\S}$, C.S. Haley ${ }^{\ddagger}$, L. S. Huang* ${ }^{*}$

* Key Laboratory for Animal Biotechnology of Jiangxi Province and the Ministry of Agriculture of China, Jiangxi Agricultural University, Nanchang 330045, China

+ Institute of Veterinary Medicine, Georg-August-University of Göttingen, Burckhardtweg 2, 37077 Göttingen, Germany

$\$$ Roslin Institute and Royal (Dick) School of Veterinary Studies, University of Edinburgh, Roslin BioCentre, Roslin, Midlothian EH25 9PS, UK

$\S$ Department of Animal Science, Center for Integrated Animal Genomics, 2255 Kildee Hall, Iowa State University Ames, Iowa 50011-3150, USA

\# PIC China, Xin'an Mansion, 99 Tian Zhou Road, Shanghai 200233, China

Accepted by Journal of Animal Science 


\section{5}

\section{A genome-wide scan for quantitative trait loci affecting limb}

\section{bone lengths and areal bone mineral density of the distal femur in a large White Duroc $\times$ Erhualian $F_{2}$ population}

Huirong Mao ${ }^{1 \dagger}$, Yuanmei Guo ${ }^{1,2 \dagger}$, Guangcheng Yang ${ }^{1}$, Bin Yang ${ }^{1}$, Jun Ren ${ }^{1}$, Sanfeng $\mathrm{Liu}^{1}$, Huashui $\mathrm{Ai}^{1}, \mathrm{Junwu} \mathrm{Ma}^{1}$, Bertram Brenig ${ }^{2}$, Lusheng Huang ${ }^{1 *}$

${ }^{1}$ Key Laboratory for Animal Biotechnology of Jiangxi Province and the Ministry of Agriculture of China, Jiangxi Agricultural University, Nanchang 330045, China

2 Institute of Veterinary Medicine, Georg-August-University of Göttingen, Burckhardtweg 2, 37077 Göttingen, Germany

${ }^{\dagger}$ These authors have the same contribution to the paper

BMC Genetics 9: 63 


\section{Acknowledgements}

I sincerely appreciate my dissertation director Prof. Dr. Dr. Bertram Brenig and the two co-directors of the dissertation Prof. Dr. Dr. Chris Haley and Prof. Dr. Dr. Lusheng Huang. Their supervisions and advice in the last four years led me to the success of completion my $\mathrm{PhD}$ degree at the Faculty of Agriculture Sciences, Georg-August-University of Göttingen. I am very grateful to Dr. Dirk-Jan de Koning, Dr. Wenhua Wei, Dr. Yinhua Huang, Dr. Monique Germerodt and Mr. Yuyun Xing for their helps when I studied in Roslin Institute and Göttingen. I also want express my appreciation to Dr. Jun Ren for his review of the thesis.

I acknowledge my friends and colleagues at Jiangxi Agricultural University in my home country, Mrs. Jun Gao, Lihua Zhou and Lin Li, and Mr. Nengshui Ding, Huashui Ai, Congyin Chen and Junwu Ma for their encouragements and their helps during the last four years.

I wish to give my sincere gratitude to all the other colleagues in Roslin Institute, Göttingen and Jiangxi Agricultural University whom I didn't listed in detail for their kindly helps in my dissertation.

Finally I would appreciate my family for their endless supports and encouragements. Without their supports and encouragements, I couldn't finish this dissertation. 


\section{List of Publications}

1. Chen C.-Y., Gilbert C.L., Yang G.-C., Guo Y.-M., Segonds-Pichon A., Ma J.-W., Brenig B., Sargent C., Affara N. and Huang L.-S. (2008) Maternal infanticide in sows: Incidence and behavioural comparisons between savaging and non-savaging sows at parturition. Appl Animl Behav Sci. 109: 238-48.

2. Chen R.-R., Day A.E., Ren J., Chen C.-Y., Ai H.-S., Ding N.-S., Ma J.-W., Guo Y.-M., Siggens K.W., Harvey K.M., Evans G.J. and Huang L.-S. (2005) Characterization of three SNPs and localization of the porcine sperm adhesion molecule (SPAM1) gene to chromosome 18 by radiation hybrid mapping. Anim Genet 36, 273-5.

3. Chistiakov D. A., Tsigenopoulos C. S., Lagnel J., Guo Y.-M., Hellemans B., Haley C. S., Volckaert F. A. M. and Kotoulas G. (2008) A combined AFLP and microsatellite linkage map and pilot comparative genomic analysis of European sea bass Dicentrarchus labrax L. Anim Genet 39(6): 623-34.

5. Guo Y.-M., Lee G. J., Archibald A. L. and Haley C. S. (2008) Quantitative trait loci for production traits in pigs: a combined analysis of two Meishan $\times$ Large White populations. Anim Genet 39(5): 486-95.

6. Guo Y. -M., Mao H. -R., Ren J., Yan X. -M., Duan Y. -Y., Yang G. -C., Ren D. -R., Zhang Z. -Y., Yang B., Ouyang J., Brenig B., Haley C. S. and Huang L. -S. (2009) A linkage map of the porcine genome from a large scale White Duroc $\times$ Erhualian resource population and evaluation of factors affecting recombination rates. Anim Genet 40(1): 47-52.

7. Huang L.-S., Ma J.-W., Ren J., Ding N.-S., Guo Y.-M., Ai H.-S., Li L., Zhou L.-H. and Chen C.-Y. (2004) Genetic variations of the porcine PRKAG3 gene in Chinese indigenous pig breeds. Genet Sel Evol 36, 481-6. 
8. Lai F.-J., Ren J., Ai H.-S., Ding N.-S., Ma J.-W., Zeng D.-Q., Chen C.-Y., Guo Y.-M. and Huang L.-S. (2007) Chinese White Rongchang Pig Does Not Have the Dominant White Allele of KIT but Has the Dominant Black Allele of MC1R. $J$ Hered 98, 84-7.

9. Li S.-J., Ren J., Yang G.-C., Guo Y.-M. and Huang L.-S. (2008) Characterization of the porcine Kisspeptins receptor gene and evaluation as candidate for timing of puberty in sows. J Anim Breed Genet 125, 219-27.

10. Mao H.-R. , Guo Y.-M.*, Yang G.-C., Yang B., Ren J., Liu S.-F, Ai H.-S, Brenig B. and_Huang L.-S. A genome-wide scan for quantitative trait loci affecting limb bone lengths and areal bone mineral density of the distal femur in a White Duroc $x$ Erhualian $\mathrm{F}_{2}$ population. BMC Genet. 2008, 9: 63.

11. Ren D.-R., Ren J., Xing Y.-Y., Guo Y.-M., Wu Y.-B., Yang G.-C., Mao H.-R. and Huang L.-S. (2008) A genome scan for quantitative trait loci affecting male reproductive traits in a White Duroc $\times$ Chinese Erhualian resouce population. $J$ Anim Sci (Online on July 3, 2008 as doi:10.2527/jas.2008-0923).

12. Ren J., Guo Y.-M., Ma J.-W. and Huang L.-S. (2006) Growth and meat quality QTL in pigs with special reference to a very large Erhualian $\times$ White Duroc resource population. In: 8th World Congress on Genetics Applied in Livestock Production, Brazil.

13. Ren J., Knorr C., Guo Y.-M., Ding N.-S., Ai H.-S., Brenig B. and Huang L.-S. (2004) Characterization of five single nucleotide polymorphisms in the porcine stearoyl-CoA desaturase (SCD) gene. Anim Genet 35, 255-7.

14. Xing Y.-Y., Ren J., Ren D.-R., Guo Y.-M., Wu Y.-B., Yang G.-C., Mao H.-R., Brenig B. and Huang L.-S. Quantitative trait loci for traits related to sperm quality and ejaculation in a White Duroc $\times$ Erhualian intercross. Anim Reprod Sci. (Online on 8 August 2008, doi: 10.1016/j.anireprosci.2008.08.008). 
15. Xu G.-L., Ren J., Ding N.-S., Ai H.-S., Guo Y.-M., Chen C.-Y. and Huang L.-S. (2006) Genetic analysis of the KIT and MC1R genes in Chinese indigenous pigs with belt-like coat color phenotypes. Anim Genet 37, 518-9.

16. Yan X.-M., Ren J., Ai H.-S., Ding N.-S., Gao J., Guo Y.-M., Chen C.-Y., Ma J.-W., Shu Q.-L. and Huang L.-S. (2004) Genetic variations analysis and characterization of the fifth intron of porcine NRAMP1 gene. Asian Austral J Anim Sci 17 1183-87.

17. Yang G.-C., Ren J., Guo Y.-M., Ding N.-S., Chen C.-Y. and Huang L.-S. (2006) Genetic evidence for the origin of an IGF2 quantitative trait nucleotide in Chinese pigs. Anim Genet 37, 179-80.

18. Yang G.-C., Ren J., Li S.-J., Mao H.-R., Guo Y.-M., Zou Z.-Z., Ren D.-R., Ma J.-W. and Huang L.-S. (2008) Genome-wide identification of QTL for age at puberty in gilts using a large intercross $F_{2}$ population between White Duroc $\times$ Erhualian. Genet Sel Evol 40: 529-39. 


\section{Curriculum vitae}

Surname:

Family name:

Address:

Tel:

Fax:

E-mail:

\section{Personal Data}

Date of birth:

Place of birth:

Sex:

Marital Status:

Nationality:

\section{Yuanmei}

Guo

Key Laboratory for Animal Biotechnology of Jiangxi Province and the Ministry of Agriculture of China, Jiangxi Agricultural University (JXAU), Nanchang 330045, China 0086-791-3813080, 0086-15879098500 0086-791-3900189

gyuanmei@hotmail.com

\section{Education and Professional Experience}

July, 2004 - Now

Institute of Veterinary Medicine, University of Göttingen

Postgraduate student for Philosophy Doctor Degree

Major: Quantitative Genetics and Molecular Biology

January, 2005 August, 2007

September, 2002 December, 2004

September, 1999 July, 2002

September, 1995 July, 1999
Roslin Institute (Edinburgh), Roslin, Midlothian EH25 9PS, UK

Visitor Scholar

Major: Quantitative Genetics

Faculty of Animal Science and Veterinary, JXAU

Lecturer

Major: Quantitative Genetics

Faculty of Animal Science and Veterinary, JXAU

Postgraduate student for Master of Science degree

Major: Quantitative Genetics

Department of Animal Husbandry and Veterinary, JXAU

Undergraduate student for Bachelor of Science degree

Major: Animal Husbandry
August 18, 1974

Jiangxi, China

Male

Single

Chinese 